[0212-7199 (2005) 22: 8; pp 383-386] ANALES DE MEDICINA INTERNA Copyright (C) 2005 ARAN EDICIONES, S.L.

An. Med. Interna (Madrid) Vol. 22, N. ${ }^{\circ} 8$, pp. 383-386, 2005

\title{
Eritema nodoso como presentación de feocromocitoma
}

\author{
S. GALLEGO DOMÍNGUEZ, F. J. PASCUA MOLINA ${ }^{1}$, A. CARO MANCILLA², \\ A. GONZÁLEZ NÚÑEZ
}

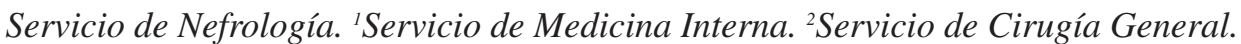
${ }^{3}$ Servicio de Anatomía Patológica. Complejo Hospitalario de Cáceres

ERYTHEMA NODOSUM BECOMING A PHEOCHROMOCYTOMA

\section{RESUMEN}

El eritema nodoso es una paniculitis septal de diversas etiologías: infecciosas, medicamentosas, secundarias a enfermedades sistémicas o idiopáticas.

Describimos el caso de una paciente de 47 años con antecedentes de hipertensión arterial de varios años de evolución, que presenta cuadro de sucesivos brotes de lesiones cutáneas eritematosas y pruriginosas en miembros inferiores, siendo diagnosticadas mediante biopsia cutánea de eritema nodoso. En el estudio etiológico se efectúa ecografía abdominal descubriendo masa sólida hipodensa de 7 × $5 \mathrm{~cm}$ situada en glándula adrenal izquierda. Determinaciones de catecolaminas y Vanilmandélico se encuentran aumentadas en suero y orina, llegándose a un diagnóstico final de feocromocitoma.

El feocromocitoma es un tumor de la médula adrenal de células cromafines derivadas de la cresta neural secretoras de catecolaminas, poco frecuente, sin diferencias entre sexos y con un pico de incidencia entre la tercera y cuarta décadas de la vida. El $90 \%$ son esporádicos, identificándose únicamente como causante de hipertensión arterial entre el 0,1 y el $0,2 \%$ de los casos.

La aparición de eritema nodoso (E.N.) como un síntoma más en el contexto evolutivo de un feocromocitoma, es una relación escasamente documentada en la bibliografía consultada. Cabría pensar en una posible coincidencia, ya que efectuada una búsqueda a través de Medline, únicamente se ha obtenido una referencia en la bibliografía mundial.

PALABRAS CLAVE: Feocromocitoma. Eritema nodoso. Hipertensión arterial.

\section{ABSTRACT}

The erythema nodosum is a septal panniculitis of several etiologies: infectious, medicamentosus, secundary to systemic disease or idiopathic cause.

The pacient is a 47 yeared-female with a hypertension history of several years of evolution, who shows the following set of sysptoms: successive rashes of erythematous and pruriginouses cutaneous lesions in inferior members, which are diagnosed by a cutaneous biopsy of erythema nodosum. In the etiology study, an abdominal echographia is made, finding a hipodensa $7 \times 5 \mathrm{~cm}$ solid mass placed in the left adrenal gland. Determinations of catecholamines and their metabolites are found to be increased in plasma and urine, with a final diagnosis of Pheochromocytoma.

The pheochromocytoma is an adrenal marrow tumour of chromaffin cells derived of the neural crest, which secrete catecholamines. It is an inusual tumour, with no gender differences and with a higher incidence between the third and fourth decade of life. Ninety per cent of the cases are rather sporadic. It causes arterial hypertension just in the 0.1 and $0.2 \%$ of total cases.

The appearence of erythema nodosum as one more symptom in the evolutionary context of a pheochromocytoma is a relation poorly documented in the examined literature. We could think it is just a possible coincidence, as searching with Medline we just find out one international bibliographic reference.

KEY WORDS: Pheochromocytoma. Erythema nodosum. Hypertension.

Gallego Domínguez S, Pascua Molina FJ, Caro Mancilla A, González Núñez. A. Eritema nodoso como presentación de feocromocitoma. An Med Interna (Madrid) 2005; 22: 383-386.

\section{INTRODUCCIÓN}

El feocromocitoma es un tumor de la médula adrenal de células cromafines derivadas de la cresta neural secretoras de catecolaminas (adrenalina, noradrenalina y menos frecuente dopamina). Tumor poco frecuente (incidencia entre 0,8-2 casos/100.000 habitantes/año), sin diferencias entre sexos y con un pico de incidencia entre la tercera y cuarta décadas de la vida. Sólo se identifica como causante de hipertensión arterial entre el 0,1 y el $0,2 \%$ de los casos (1).

Es importante su diagnóstico precoz ya que es una causa curable de hipertensión arterial además de la alta mortalidad asociada (2). El $80 \%$ de los tumores son unilaterales y de localización derecha, sin una clara explicación. Un 10\% son

Trabajo aceptado: 11 de abril de 2005 
bilaterales y otro $10 \%$ son extra-suprarrenales, siendo denominados paragangliomas (3).

El 90\% son esporádicos y el 10\% restante tiene una presentación familiar con herencia autosómica dominante, bien dentro de síndromes hereditarios o formando parte de los síndromes de neoplasia endocrina múltiple (MEN) tipo 2A y $2 \mathrm{~B}$ (4). Menos del 10\% de ellos son malignos. El diagnóstico se basa en la demostración de la hiperproducción de catecolaminas y metanefrinas, aplicando posteriormente técnicas de localización: ecografía abdominal, TAC, RMN y la gammagrafía con metayodobenzilguanidina (MIGB) (5). El diagnóstico de malignidad se basa en la extensión local o la presencia de metástasis. No existe ningún hallazgo histológico que permita diferenciar las formas benignas de las malignas (6). El tratamiento del feocromocitoma suele ser quirúrgico, aunque en las formas malignas se requieren tratamientos adicionales, como el I-MIBG o la quiomioterapia (1).

\section{CASO APORTADO}

Mujer de 47 años de edad, con antecedentes personales de HTA de varios años de evolución, tiroiditis autoinmune con bocio polimicronodular y galactorrea por hiperprolactinemia $2^{\mathrm{a}}$, en tratamiento habitual con levotiroxina 100/125 $\mu \mathrm{g}$ alternando, $\alpha$ bloqueantes y Calcio antagonistas.

Ingresada por cuadro de artromialgias generalizadas, odinofagia ocasional, fiebre termometrada, hasta $38,5^{\circ}$, y malestar general con posterior aparición de lesiones eritematosas y pruriginosas /dolorosas con tumefacción en ambos tobillos y regiones pretibiales. No presenta otros datos de interés. En la exploración física destaca: T.A. 150/100. Ausencia de fiebre, en el momento del ingreso. Buen estado general, no adenopatías latero cervicales ni en otras regiones ganglionares. Ausencia de bocio palpable. Tórax: A.P.: murmullo vesicular conservado, sin ruidos patológicos. A.C.: Tonos puros y rítmicos, sin soplos ni extrasístoles, refuerzo del $2^{\circ}$ tono. Abdomen: blando y depresible sin organomegalias ni puntos dolorosos ni masas. Extremidades: lesiones eritematosas duras, ligeramente sobre- elevadas con palidez central, dolorosas en ambas regiones pretibiales. También tumefacción y aumento del calor en ambos tobillos y rodillas acompañado de impotencia funcional. Exploraciones complementarias: hematología: Hb: 10,9, HCT: 32,2, VCM: 87; leucos: 11.200 (NE: 79\%, Ly: 11\%, Mo: 7,3\%), plaq.: 739.000), TQ: 97\%, fib: 732 .

El estudio bioquímico de glucemia, urea, creatinina, Ac. úrico, iones, lípidos, enzimática hepática, así como de hormonas tiroideas fue normal. Estudio férrico con Fe sérico: 14, ferritina: 38, transferrina: 231. Mantoux, BK (repetidos), hemocultivos, así como cultivo de exudado faríngeo:Negativos. Serología frente a Brucella, VHC, VHB, CMV, VEB, Rickettsia, Leptospira, sífilis, Yersinia, Borrelia y Chlamidia: negativas. PCR: 25, ASLO: 231, Factor Reumatoide: 3,1. Complemento: normal. ANA: negativos, ECA: normal. Sistemático de orina normal y urocultivos negativos.

Rx. de tórax y de senos paranasales normales. EKG: RS a 100 $\mathrm{lpm}, \mathrm{PR}$ corto, eje a $45^{\circ}$, sin alteraciones de repolarización ni de conducción. Fondo de ojo: normal. Se efectuó biopsia cutánea de las lesiones de miembros inferiores (en dos intentos), observándose una paniculitis septal, diagnosticándose de eritema nodoso sin imágenes de vasculitis.

Durante su evolución precisó varios ingresos, presentando nuevos brotes de lesiones cutáneas de EN, con la misma distribución en los miembros inferiores, añadiéndose en el último cuadro de dolor lumbar de características fijas y constantes de tipo sordo, sin sintomatología urinaria ni cambios en las características de la orina. En la exploración física sólo varía la aparición de puño percusión renal derecha (+). De las pruebas complementarias realizadas destacan: plaquetas: 589.000. Fib: 521, leucos: 11.800 (fórmula normal). PCR: 32. Factor reumatoide: 2,2. Marcadores tumorales (SCC, beta HCG, AFP, Ca 19,9, CEA, Ca 15,3, Ca 125) negativos, así como ACTH y Cortisol normales.

Catecolaminas fraccionadas en orina:

-Adrenalina: 540.

-Noradrenalina: 761.

-Dopamina: 675.

-Ac. vanilmandélico: 21,5.

Catecolaminas en suero:

-Adrenalina: 1.074

-Noradrelina: 599.

-Dopamina: 448.

En la ecografía abdominal se objetivó una masa sólida hipodensa de 7 x $5 \mathrm{~cm}$, en área teórica de glándula adrenal izquierda con contenido ecogénico declive y algunos ecos fuertes lineales, probablemente por sangrado. Posteriormente, en TAC Abdominal (Fig. 1), se apreció una masa adrenal izquierda de 7 x $5 \mathrm{~cm}$, sólida, heterogénea, de límites bien definidos, que presentaba realce de contraste con zonas hipodensas en su interior por necrosis. Por tanto, el diagnóstico final de la paciente fue:

- HTA secundaria a feocromocitoma en glándula adrenal izquierda.

-Eritema nodoso.

- Tiroiditis autoinmune en situación eutiroidea.

- Hiperprolactinemia secundaria a tratamiento con Levotiroxina

Con los diagnósticos anteriormente mencionados se inició tratamiento médico con alfa y beta-bloqueantes como paso previo a intervención quirúrgica, efectuándose suprarrenalectomía izquierda por vía laparoscópica (Fig. 2), así como esplenectomía por desgarro de la cápsula con hemorragia subcapsular, mediante minilaparotomía.

En el estudio anátomo-patológico se apreció un tumor suprarrenal izquierdo, diagnosticándose de feocromocitoma, con un tamaño de $6,5 \mathrm{~cm}$ de diámetro y $135 \mathrm{~g}$ de peso con inmunorreactividad para Cromogranina, Sinaftofisina, CD-56 y NSE positivas, así como para CAM 5-2, Vimentina, S-100 y EMA negativas. Presentaba un índice de proliferación celular (Ki-67) bajo, menor del 10\%. El bazo presentaba desgarro de la cápsula con hemorragia subcapsular, con el resto de pulpa esplénica normal.

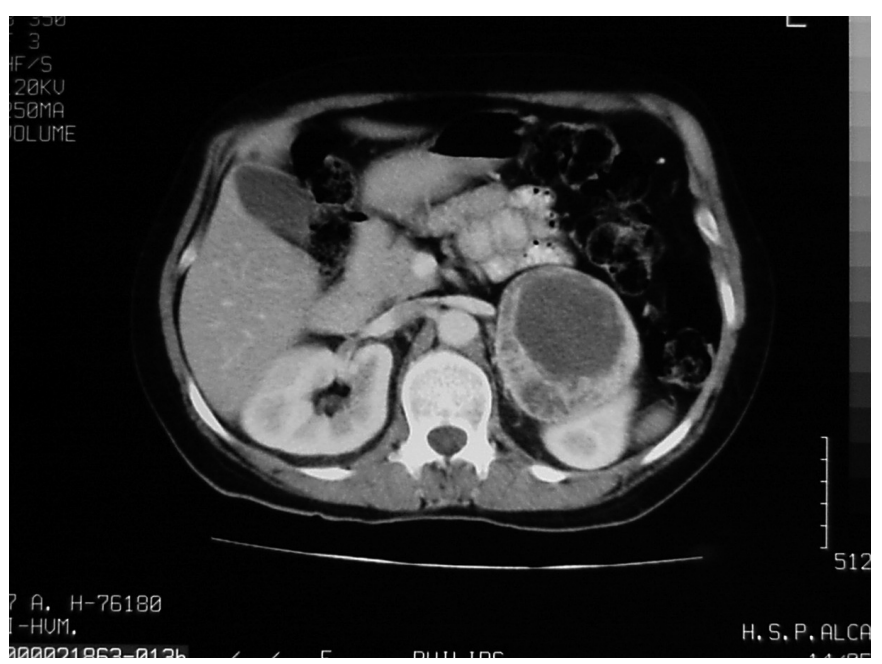

Fig. 1. Imagen CT abdominal: masa adrenal izquierda de $7 \times 5 \mathrm{~cm}$, sólida, heterogénea, de límites bien definidos, que presenta realce de contraste con zonas hipodensas en su interior por necrosis. 


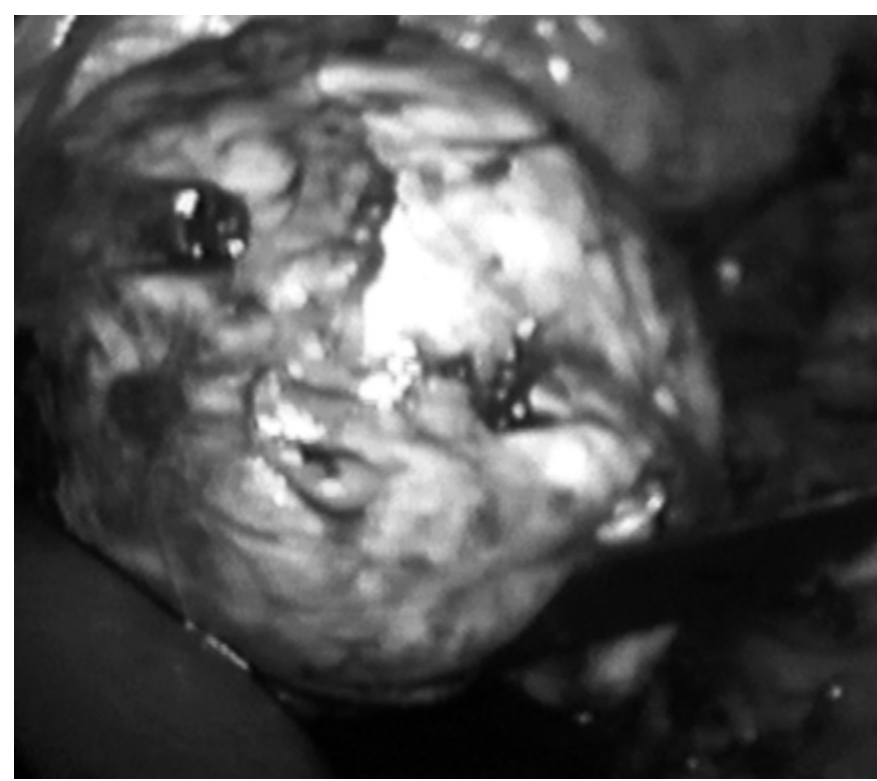

Fig. 2. Imagen laparoscópica de pieza quirúrgica de $6,5 \mathrm{~cm}$ de diámetro máximo y superficie lisa.

\section{DISCUSIÓN}

El feocromocitoma es un tumor de la médula adrenal de células cromafines derivadas de la cresta neural secretoras de catecolaminas, con una incidencia entre 0,8-2 casos/100.000 habitantes /año, sin diferencias entre sexos y con un pico de incidencia entre la tercera y cuarta décadas de la vida, identificándose como causante de hipertensión arterial únicamente entre el 0,1 y el 0,2\% de los casos (1). Es importante su diagnóstico precoz ya que es una causa curable de hipertensión arterial además de la alta mortalidad asociada (2). El 90\% son esporádicos y el 10\% restante tiene una presentación familiar con herencia autosómica dominante, bien dentro de síndromes hereditarios o formando parte de los síndromes de neoplasia endocrina múltiple (MEN) tipo 2A y 2B (4), por lo que deberíamos plantearnos la necesidad de efectuar estudio familiar mediante screening con análisis del protooncogen cret en búsqueda de un posible feocromocitoma en individuos en los que se demuestre el síndrome de neoplasia endocrina múltiple (MEN). El diagnóstico se basa en la demostración de la hiperproducción de catecolaminas y metanefrinas, como es el caso de nuestra paciente, localizándose posteriormente mediante técnicas de imagen, entre las cuales destacan la Ecografía abdominal, TAC, RMN o gammagrafía con MIGB (5). En caso de no localización por técnicas no invasivas existe la opción de la arteriografía abdominal o la cateterización venosa con toma de muestras a distintos niveles de la vena cava superior e inferior. En nuestra paciente, la localización de la masa suprarrenal se consiguió mediante ecografía y TAC, no siendo necesarias el resto de pruebas. El diagnóstico de malignidad se basa en la extensión local o la presencia de metástasis, ya que no existe ningún hallazgo histológico que permita diferenciar las formas benignas de las malignas (6). El tratamiento del feocromocitoma suele ser quirúrgico, aunque en las formas malignas se requieren tratamientos adicionales, como el I-MIBG o la quiomioterapia
(1). La aparición de eritema nodoso (EN) (5), como un síntoma más en el contexto evolutivo de un feocromocitoma, es una relación escasamente documentada en la bibliografía consultada. De hecho, en la lista de diagnósticos diferenciales (7) que debemos plantearnos ante el citado diagnóstico de EN (Tabla I) no aparece citado el feocromocitoma por ninguno de los autores consultados. Tampoco aparece la citada entidad dentro de las posibles lesiones cutáneas acompañantes de un feocromocitoma u otros síndromes cutáneos paraneoplásicos, recogidos en la tabla II. Sólo nos restaría pensar en una posible coincidencia, (efectuada una búsqueda a través de Medline únicamente se ha obtenido una referencia en la bibliografía mundial) (5), si no fuera porque, en las sucesivas

\section{TABLA I}

\section{DIAGNÓSTICO DIFERENCIAL ANTE UN ERITEMA NODOSO}

\begin{tabular}{lc}
\hline Infecciosas & Enf. sistémicas \\
\hline Estreptocócica & Leucemias/linfomas \\
Brucelosis & Sarcoidosis \\
Tuberculosis & Fiebre reumática \\
Hepatitis B/C & Enf. de Behçet \\
Turalemia & Ell (CU/EC) \\
Sífilis & Medicamentos: \\
Rickettsia & Anticonceptivos orales \\
Leptospirosis & Penicilina \\
Coccidiodomicosis & Sulfonamidas/sulfonas \\
Micosis & Barbitúricos \\
Bartonella (arañazo de gato) & Hidantoína \\
Psitacosis & Fenacetina \\
Histoplasmosis & Salicilatos \\
Infección por CMV & Yoduros \\
Mononucleosis & Progesterona \\
Idiopáticas & IECAS/ARA II \\
\hline
\end{tabular}

TABLA II

\begin{tabular}{l} 
TABLA II \\
LESIONES CUTÁNEAS ACOMPAÑANTES DE UN \\
FEOCROMOCITOMA U OTROS SÍNDROMES CUTÁNEOS \\
PARANEOPLÁSICOS \\
\hline Enf. ampollosas: pénfigo paraneoplásico \\
Trastornos de la queratinización: Acantosis nigrans, rritrodermia, ictiosis \\
Eritemas figurados: Eritema giratum, necrolítico, anular \\
Dermatosis neutrofílicas \\
Enf. del colágeno: dermatomiositis \\
Enf. de deposito: amiloidosis \\
Trastornos de pigmentación: melanosis \\
Trastornos vasculares: vasculitis, eritromelalgia, Tromboflebitis migrans, \\
Flushing \\
Otros: paquidermoperiostosis, hipertricosis lanuginosa, etc.
\end{tabular}


revisiones que ha seguido la paciente, dentro del control normal de su postoperatorio, no ha vuelto a presentar las lesiones cutáneas correspondientes a eritema nodoso además de tener correctamente controlada la TA sin precisar medicación hipotensora alguna, lo cual nos induce a pensar en una posible vinculación causa-efecto.

\section{Bibliografía}

1. Francisco G, Lecube A, Tovar JL, Mesa J. Feocromocitoma extraadrenal maligno: una causa rara de hipertensión arterial. Hipertensión 2003; 20 : $82-4$.

2. Manger WM, Gifford RW. Pheochromocytoma. J Clin Hypertens (Greenwich) 2002; 4: 62-72.

3. García Rodríguez J, Fernández Gómez JM, Jalón Monzón A, et al. Extra adrenal pheochromocytoma. Report of two cases. Arch Esp Urol 2003 56: $310-3$.

4. Rao F, Keiser HR, O'Connor DT. Malignant pheochromocytoma. Chromaffin granule transmitters and response to treatment. Hypertension. 2000; 36: 1045-52.

5. Noila JM, Valverde J, Rozadilla A, Fiter J, Gómez Vaqueroa C. Manifestaciones mucocutáneas en las enfermedades reumáticas. Jano 2000; 59 : 44-51.

6. De Toma G, Leticia C, Cavallaro G, Giacchino V, Mosiello G, Cavall Basile U. Malignant pheochromocytoma. Personal experience, review the literature. Ann Ital Chir 2002; 73: 413-8.

7. Brodell RT, Mehrabi D. Underlying causes of erythema nodosum Lesions may provide clue to systemic disease. Postgraduate Medicine. Minneapolis 2000; 108: 147.

8. Oishi S, Koga B, Sasaki M, Umeda T, Sato T. Pheochromocytoma associated with Behcet's disease. Jpn J Clin Oncol 1989; 19: 283-6. 